\title{
Effects of spinal cord stimulation in angina pectoris induced by pacing and possible mechanisms of action
}

\author{
C Mannheimer, T Eliasson, B Andersson, C-H Bergh, L-E Augustinsson, H Emanuelsson, \\ F Waagstein
}

\begin{abstract}
Objective-To investigate the effects of spinal cord stimulation on myocardial ischaemia, coronary blood flow, and myocardial oxygen consumption in angina pectoris induced by atrial pacing.

Design-The heart was paced to angina during a control phase and treatment with spinal cord stimulation. Blood samples were drawn from a peripheral artery and the coronary sinus.

Setting-Multidisciplinary pain centre, department of medicine, Ostra Hospital, and Wallenberg Research Laboratory, Sahlgrenska Hospital, Gothenburg, Sweden.
\end{abstract}

Subjects-Twenty patients with intractable angina pectoris, all with a spinal cord stimulator implanted before the study.

Results-Spinal cord stimulation increased patients' tolerance to pacing $(p<0.001)$. At the pacing rate comparable to that producing angina during the control recording, myocardial lactate production during control session turned into extraction $(p=0.003)$ and, on the electrocardiogram, ST segment depression decreased, time to ST depression increased, and time to recovery from ST depression decreased $(p=0.01 ; p<0.05$, and $p<0.05$, respectively). Spinal cord stimulation also reduced coronary sinus blood flow $(p=0.01)$ and myocardial oxygen consumption $(p=0.02)$. At the maximum pacing rate during treatment, all patients experienced anginal pain. Myocardial lactate extraction reverted to production $(p<0.01)$ and the magnitude and duration of ST segment depression increased to the same values as during control pacing, indicating that myocardial ischaemia during treatment with spinal cord stimulation gives rise to anginal pain.

Conclusions-Spinal cord stimulation has an antianginal and anti-ischaemic effect in severe coronary artery disease. These effects seem to be secondary to a decrease in myocardial oxygen consumption. Furthermore, myocardial ischaemia during treatment gives rise to anginal pain. Thus, spinal cord stimulation does not deprive the patient of a warning signal.

C Mannheimer, head

T Eliasson, senior registrar

Division of Cardiology, Sahlgrenska Hospital, S-413 45 Gothenburg, Sweden

B Andersson, senior registrar C-H Bergh, senior registrar H Emanuelsson, medical director

F Waagstein, senior physician

Department of Neurosurgery, Sahlgrenska Hospital

L-E Augustinsson, senior physician

Correspondence to: Dr Mannheimer.

BMF 1993;307:477-80

Spinal cord stimulation has been used for several years to relieve chronic neurogenic pain. ${ }^{12}$ Since 1976 there have also been several reports on the pain relieving effect of spinal cord stimulation in peripheral vascular disease, associated with an increase in local blood flow and promotion of the healing of ischaemic ulcers. ${ }^{3-5}$

There are also reports on the antianginal effect of spinal cord stimulation in coronary artery disease. The exact mechanisms behind these effects are not yet known, but there are indications that the antianginal effect of the treatment is secondary to a decrease in myocardial ischaemia. ${ }^{\circ} 7$

Atrial pacing is commonly used to study myocardial ischaemia. ${ }^{8}$ The heart is paced by means of a catheter in the coronary sinus. The frequency is increased step by step up to a level where the patient reports angina because of the increased heart rate, which increases the myocardial oxygen consumption. The method has several advantages in the experimental situation ${ }^{8}$ - it is possible to stress the heart without major changes in the patients' condition and with a stable position of the catheter in the coronary sinus.

The aim of this study was to investigate whether spinal cord stimulation will decrease myocardial ischaemia in angina pectoris induced by pacing and, if so, whether the treatment will affect coronary blood flow or myocardial oxygen consumption, or both.

\section{Patients and methods}

Twenty patients (15 men; mean age 65 years, range 51-79 years) with severe angina pectoris (New York Heart Association functional class III-IV) were included in the study. The antianginal medication being given was considered to be optimal. The patients had previously had a spinal cord stimulator implanted for anti-anginal treatment. Fifteen patients had suffered myocardial infarction more than six months before the study. All patients had chest pain and ST segment depression of the anterior wall on electrocardiographic examination during a maximum symptom limiting bicycle ergometer test. Fifteen patients had recurrent angina after a previous coronary bypass operation and five patients were considered unsuitable for bypass surgery.

One patient had a left main stem lesion (previously operated on), 15 patients had three vessel disease, and two patients had two vessel disease. Two patients had been considered unsuitable for bypass surgery without previous coronary arteriography.

No antianginal medication was given 12 hours before the pacing procedures, and spinal cord stimulation treatment was not permitted 48 hours before the trials to avoid interference from possible long term effects of the treatment. The patients were studied in the morning in a non-sedated, fasting state. All patients had had a spinal cord stimulator implanted by the same surgeon, as described earlier. ${ }^{6}$ The time from implantation to catheterisation varied from one month to seven years.

The study was approved by the ethical committee of the University of Gothenburg. Verbal and written information was given to all patients.

\section{CATHETERISATION}

A thermodilution pacing catheter (Wilton-Webster Laboratory, USA) was placed in or near the great cardiac vein of the coronary sinus, as described previously. ${ }^{10}$ A polyethylene catheter was inserted into a peripheral artery. Blood samples were simultaneously drawn from the catheters in the artery and the coronary sinus.

\section{MEASUREMENTS}

The electrocardiogram and blood pressure were recorded continuously. The coronary sinus blood flow was determined by means of the continuous infusion thermodilution method as described previously. ${ }^{11}$ 
Lactic acid concentration was assayed with an enzymatic method (Lactate Analyzer 640, Roche BioElectronics). The lactate analyses were made in duplicate with a mean difference of $2.5 \%$, which is in accordance with previous results in our laboratory.

The figure summarises the design of the study. Blood samples were drawn simultaneously from a peripheral artery and the coronary sinus at rest during steady state. Blood pressure and coronary sinus blood flow were measured simultaneously. Atrial pacing was then started at a frequency of 80 beats a minute or 10 beats above resting heart rate. The pacing rate was increased by 10 beats a minute every minute, continuing until the patient experienced moderate anginal pain (control rate). Measurements and blood sampling were then repeated, after which pacing was stopped and the patient was allowed to rest for 30 minutes. Treatment with spinal cord stimulation was then started and the patient was allowed to rest for another 20 minutes during stimulation. New baseline measurements were made and blood samples were taken. The pacing routine was then repeated. New recordings were made at the pacing rate comparable to the control rate (pacing rate 1). If the patient experienced no chest pain at this level, the pacing rate was increased until the patient considered the chest pain to be of the same degree as during the control session (pacing rate 2). If the patient did not experience any pain at a frequency of 30 beats a minute above the control pacing rate, or more pronounced ST depression appeared on the electrocardiogram than at the control rate, the pacing was stopped. The maximum pacing frequency was set to 170 beats a minute.

The reason for choosing this design was the possibility of showing an effect of spinal cord stimulation on myocardial lactate metabolism, anginal threshold, and toleration of pacing to a heart rate higher than control pacing. Firstly, comparison of control pacing to pacing to the rate at which angina was produced during the control recording (comparable heart rate) during spinal cord stimulation would allow us to detect a possible improvement in myocardial lactate metabolism. This assumption was based on the hypothesis that the treatment, according to our clinical and experimental experience of spinal cord stimulation in patients with angina pectoris, would improve myocardial metabolism of lactate. Secondly, an increase in angina threshold and ability to tolerate a higher pacing rate would allow us to show the clinical value of spinal cord stimulation. Thirdly, if severe pain, definite ST-T depression, and lactate production occurred at the higher pacing rate it would allow us to differentiate between pain relief and an anti-ischaemic effect.

\section{CALCULATIONS}

The myocardial oxygen consumption $(\mathrm{ml} / \mathrm{min})$ was calculated as the difference in oxygen measured in samples taken from a peripheral artery and the coronary sinus multiplied by coronary sinus blood flow. The myocardial lactate extraction ratio was expressed as a percentage: 100 times (arterial lactate concentration minus the coronary sinus lactate concentration) divided by the arterial lactate concentration.

Time to angina (seconds) and time to ST segment depression (seconds) were calculated as the time from the start of atrial pacing until the occurrence of pain and to a $1 \mathrm{~mm}$ increase in ST segment depression, respectively. Recovery time for angina (seconds) and recovery time for ST segment depression (seconds) were calculated as the time from stopping pacing to disappearance of pain and disappearance of the increase in ST segment depression, respectively.

The rate-pressure product was calculated by multiplying the heart rate by the systolic blood pressure.

\section{STATISTICAL MBTHODS}

When values during control pacing and pacing with spinal cord stimulation were compared the difference between the corresponding values was used. A nonparametric test was applied to obtain accurate $p$ values regardless of the underlying distributions. Accuracy is more critical when the $p$ values are low. The test used, Fisher's test for paired comparisons, 12 is the nonparametric test closest to the parametric $t$ test for paired differences. The test belongs to the class of permutation tests." Unlike Wilcoxon's test, Fisher's test is not based on ranks but on the original differences. The advantage of using this test, rather than Wilcoxon's test or the sign test, is that Fisher's test has been shown to be the most powerful test when the underlying distributions of differences are close to normal. ${ }^{14}$ Two tailed tests were used; means and standard deviations are given.

Data were analysed by making the following comparisons (figure): firstly, at resting levels during control conditions and spinal cord stimulation; secondly, at the maximum rate of control pacing and the comparable pacing rate during spinal cord stimulation (pacing rate 1); thirdly, at the maximum rates during control pacing and spinal cord stimulation (pacing rate 2); finally, during spinal cord stimulation at the comparable heart rate (pacing rate 1 ) and the maximum heart rate (pacing rate 2 ).

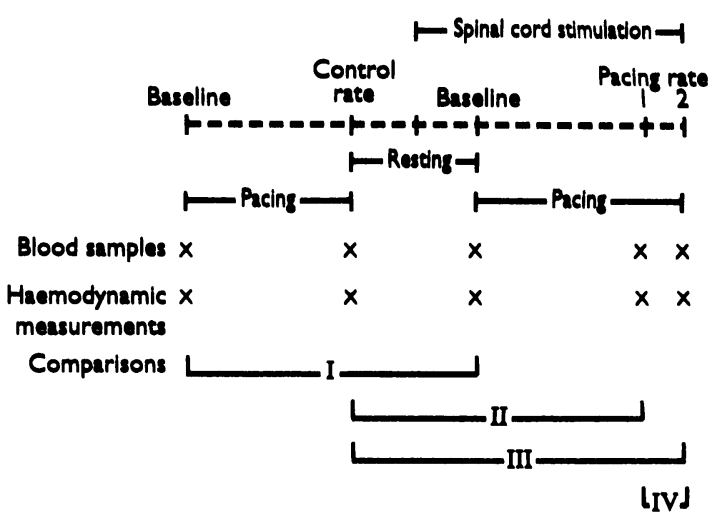

Schedule, procedure and statistical comparisons. Roman numerals refer to tests of paired comparisons.

\section{Results}

Tables I and II show the effects of spinal cord stimulation. At rest heart rate increased significantly during treatment with spinal cord stimulation $(p<0.001)$.

All patients experienced chest pain during control pacing. Tolerance of pacing increased during treatment with spinal cord stimulation (149 (SD 15) beats/min $v 128$ (13) beats $/ \mathrm{min} ; p<0.001$ ). Time to angina increased and recovery time for angina decreased during spinal cord stimulation (1038 (318) s $v 219(156) \mathrm{s}(\mathrm{p}<0.001)$ and $72(49) \mathrm{s} v 321$ (331) s $(p=0.02)$, respectively.

During control pacing, there was a net myocardial production of lactate, which reverted to extraction during spinal cord stimulation at pacing rate 1 $(8 \%(21 \%) v-8 \%(33 \%) ; p=0.003)$. Furthermore, during treatment with spinal cord stimulation compared with control pacing; ST segment depression decreased $(-1.0(0.6) \mathrm{mm} v-1.8(0.9) \mathrm{mm} ; \mathrm{p}=0.001)$; time to ST segment depression increased (425 (213) s, $v 289$ (196) s; $p=0.02$ ); and recovery time for ST segment depression decreased (480 (320) s v 973 (676) s; $\mathrm{p}=0.03$ ) (table II).

During treatment with spinal cord stimulation, coronary sinus blood flow and myocardial oxygen consumption decreased at pacing rate 1 in comparison 


\begin{tabular}{|c|c|c|c|c|c|c|c|c|c|c|c|c|c|c|c|c|c|}
\hline & \multirow{3}{*}{\multicolumn{2}{|c|}{ Atrest }} & \multirow{4}{*}{$\begin{array}{c}\text { Control } \\
\text { nate }\end{array}$} & & & \multirow{2}{*}{\multicolumn{3}{|c|}{ At rent: control u utimulation }} & \multicolumn{9}{|c|}{ During pacing } \\
\hline & & & & \multirow{2}{*}{\multicolumn{2}{|c|}{ During itimulation }} & & & & \multicolumn{3}{|c|}{ Control e pacing ! } & \multicolumn{3}{|c|}{ Control u pacing 2} & \multicolumn{3}{|c|}{ Pueing 1 upucing 2} \\
\hline & & & & & & \multirow{2}{*}{$\begin{array}{c}\text { Mean } \\
\text { (SD) } \\
\text { difforence }\end{array}$} & \multirow{2}{*}{$\begin{array}{l}95 \% \\
\text { Confdence } \\
\text { interval }\end{array}$} & \multirow[b]{2}{*}{ pValue } & Moon & $95 \%$ & & Mean & $95 \%$ & & & $050 \%$ & \\
\hline & Control & $\begin{array}{c}\text { With } \\
\text { itimulation }\end{array}$ & & Pacing! & Pacing 2 & & & & difference & interval & p Value & difference & $\begin{array}{l}\text { interval } \\
\text { inter }\end{array}$ & p Value & difference & $\begin{array}{l}\text { Datheornal } \\
\text { inter }\end{array}$ & pValue \\
\hline \multirow{4}{*}{ 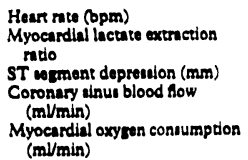 } & $67(13)$ & $75(14)$ & $128(13)$ & $128(14)$ & $140(15)$ & $-7(8)$ & $-11 t 0-4$ & $<0.001$ & $0(1)$ & -1100 & NS & $-2 !(7)$ & $-26 t 0-18$ & $<0.001$ & $-22(7)$ & -25 to -18 & $<0.001$ \\
\hline & $\begin{array}{r}24(19) \\
-0.2(0.2)\end{array}$ & $\begin{array}{c}22(13) \\
-0.1(0.2)\end{array}$ & $\begin{array}{l}-8(33) \\
-1.8(0.9)\end{array}$ & $\begin{array}{c}8(21) \\
-1.0(0.6)\end{array}$ & $\begin{array}{l}-3(21) \\
-1.8(1.0)\end{array}$ & $\begin{aligned} & 2(18) \\
&-0.1(0.2)\end{aligned}$ & $\begin{array}{l}-610.10 \\
-0.2100 .1\end{array}$ & $\begin{array}{l}\text { NS } \\
\text { NS }\end{array}$ & $\begin{array}{l}-16(22) \\
-0.8(0.9)\end{array}$ & $\begin{array}{l}-2610-5 \\
-1 \cdot 160-0.5\end{array}$ & $\begin{array}{l}0.003 \\
0.001\end{array}$ & $\begin{array}{l}-2(26) \\
-0.1(0.4)\end{array}$ & $\begin{array}{l}-151011 \\
-0.4100 .2\end{array}$ & $\begin{array}{l}\text { NS } \\
\text { NS }\end{array}$ & $13(19)$ & 41023 & 0.01 \\
\hline & $99(57)$ & $95(02)$ & $136(65)$ & $124(63)$ & $145(53)$ & $4(31)$ & $-11+019$ & NS & $20(30)$ & 31035 & 0.01 & $-9(43)$ & $-34: 010$ & NS & $\begin{array}{r}0.9(0.5) \\
-30(31)\end{array}$ & $\begin{array}{r}0.5 \text { to } 1.3 \\
-48 \text { to }-12\end{array}$ & $\begin{array}{l}0.004 \\
0.003\end{array}$ \\
\hline & $13(8)$ & $14(10)$ & $19(11)$ & $16(9)$ & $19(9)$ & $-1(8)$ & -5003 & NS & $4(6)$ & 1107 & 0.02 & $0(8)$ & -5105 & NS & $-4(4)$ & $-7 t 0-2$ & 0.002 \\
\hline
\end{tabular}

NS-not uiguifcent:

TABLB II-Effects of spinal cord stimulation on time (seconds) to and recovery time for angina and ST segment depression. Values are means (SD)

\begin{tabular}{|c|c|c|c|c|c|}
\hline & Control & $\begin{array}{l}\text { Spinal cord } \\
\text { stimulation }\end{array}$ & $\begin{array}{c}\text { Mean } \\
\text { difference } \\
\text { (paired SD) }\end{array}$ & $\begin{array}{c}95 \% \\
\text { Confidence } \\
\text { interva! }\end{array}$ & p Value \\
\hline $\begin{array}{l}\text { Time to angina } \\
\text { Recovery time for angina } \\
\text { Time to ST regment depression } \\
\text { Recovery time for ST semment depresuion }\end{array}$ & $\begin{array}{l}219(156) \\
321(331) \\
289(196) \\
973(676)\end{array}$ & $\begin{array}{l}1038(318) \\
72(49) \\
425(213) \\
480(320)\end{array}$ & $\begin{array}{r}-819(340) \\
270(321) \\
-137(138) \\
467(393)\end{array}$ & $\begin{array}{c}-1015 \text { to }-622 \\
66 \text { to } 474 \\
-243 \text { to }-30 \\
104 \text { to } 830\end{array}$ & $\begin{array}{c}<0.001 \\
0.02 \\
0.02 \\
0.03\end{array}$ \\
\hline
\end{tabular}

to control pacing (124 (63) $\mathrm{ml} / \mathrm{min} v 136(65) \mathrm{ml} / \mathrm{min}$ $(p=0.01)$ and $16(9) \mathrm{ml} / \mathrm{min} v 19(11) \mathrm{ml} / \mathrm{min}(p=0.02)$ respectively) (table I).

At the maximum heart rate (pacing rate 2), the net myocardial extraction reverted to production $(p-0.01)$, and ST segment depression increased to the same extent as during control pacing $(p=0.004)$ (table I). The degree of coronary sinus blood flow and myocardial oxygen consumption during spinal cord stimulation at the maximum heart rate increased to the same degree as during control pacing $(p=0.003$ and $p=0.002$, respectively) (table I).

\section{Discussion}

Atrial pacing is considered to be a valid and reproducible method to assess myocardial ischaemia if the heart rate is quickly increased to the anginal level and the recovery period between control and treatment sessions is at least 45 minutes. . $^{15-10}$ In the present study the heart rate was increased by 10 beats a minute and the recovery period was at least 50 minutes. The present design may therefore be considered valid and reproducible. As spinal cord stimulation may have long term effects the treatment was always performed as the second intervention in all patients so as to avoid interference with control pacing.

The patients in this study produced lactate during control pacing, and since only myocardial production (that is, negative extraction ratio) can be considered abnormal and an indicator of myocardial ischaemia it can be concluded that the blood samples represent ischaemic areas of the myocardium. ${ }^{10-21}$

The findings from the present investigation accord with earlier studies of transcutaneous electrical nerve stimulation and spinal cord stimulation in angina pectoris, in which increased pacing tolerance, decreased ST segment depression, and improved myocardial lactate metabolism have been shown. ${ }^{6710223}$ Possible mechanisms of the anti-ischaemic effect of spinal cord stimulation are an increase in coronary blood flow, a decrease in myocardial oxygen consumption, or a direct, pain inhibiting effect which decreases myocardial oxygen consumption secondarily.

\section{POSSIBLE MBCHANISMS}

The coronary sinus blood flow decreased in response to spinal cord stimulation. In an earlier study, spinal cord stimulation proved to have beneficial effects, measured as decreased anginal time and a decreased duration and magnitude of ST segment depression during exercise compared with control values, but there were no significant changes in regional myocardial perfusion, as measured by "K positron emission tomography during exercise. ${ }^{24}$ The results of three haemodynamic studies of the effects of transcutaneous electrical nerve stimulation in angina pectoris showed that there was no increase in coronary sinus blood flow during treatment, despite there having been an antiischaemic effect in terms of improved myocardial lactate metabolism..$^{19223}$ In addition, studies of the effects of spinal cord stimulation on cerebral blood flow and the effect of transcutaneous electrical nerve stimulation of local blood flow in skin flaps after reconstructive surgery have shown an increase in flow. ${ }^{23} 20$ These studies, however, dealt with changes in blood flow in tissues supplied by normal arterial and arteriolar vessels. The conditions will probably be quite different in tissues with vessels which are severely damaged by arteriosclerosis, as in coronary artery disease, where the physiological prerequisites for vasodilatation are limited. Thus, the results from the present and earlier studies do not support the hypothesis that the antiischaemic effect of electrostimulation in coronary artery disease is secondary to a general increase in blood flow.

With regard to a decrease in myocardial oxygen consumption as the mechanism, it is well known that coronary venous oxygen tension is relatively constant during changes in myocardial oxygen consumption. There is strong evidence that the coronary blood flow depends largely on autoregulatory mechanisms. ${ }^{27}$ Furthermore, one animal study showed a linear relation between myocardial oxygen consumption and coronary blood flow. ${ }^{29} \beta$ Blockade gave rise to a reduction in both oxygen consumption and blood flow but did not affect the relation between these variables. It has also been proposed that myocardial hypoxia leads to an increase in the interstitial concentration of adenosine, which produces arteriolar vasodilatation and an increase in blood flow, thus compensating for the decrease in myocardial oxygen tension. ${ }^{30}$ Thus, if spinal cord stimulation induces a decrease in myocardial oxygen consumption, there will also be a decrease in coronary blood flow, as in the present investigation.

With respect to direct inhibition of pain, anginal pain has been shown to induce an increase in sympathetic activity, which is probably secondary to the pain." There is also reason to believe that spinal cord stimulation has a direct pain inhibiting effect. For example, in one animal study Foreman et al found that spinal cord stimulation attenuated anginal pain by reducing the activity of the spinal thalamic tract neurones which transmit nociceptive somatic and cardiac impulses. 32 There are also other studies which indicate that treatment which has a direct pain inhibiting effect also decreases the activity in the cardiac sympathetic nerves and thereby decreases the myocardial oxygen consumption." s"

\section{CONCLUSION}

The results of the present investigation showed beneficial effects of spinal cord stimulation in terms of 


\section{Clinical implications}

- Many patients with coronary artery disease suffer from intractable angina pectoris in spite of optimal medical and surgical therapy

- Spinal cord stimulation has proved to be an effective method to relieve angina pectoris in these patients; the anti-anginal effect seems, from earlier studies, to be associated with a reduction in myocardial ischaemia

- This study confirms that spinal cord stimulation has an anti-ischaemic effect in angina pectoris that can be induced by atrial pacing-this effect is probably mediated by a reduction in myocardial oxygen consumption.

- Myocardial ischaemia during treatment with spinal cord stimulation gives rise to anginal pain-that is, the treatment does not conceal symptoms of myocardial ischaemia

- Spinal cord stimulation seems to be a therapeutic possibility in patients with angina pectoris when conventional strategies of management have been exhausted increased tolerance to atrial pacing, improved myocardial lactate metabolism, and decreased magnitude and duration of ST segment depression at comparable pacing frequencies, suggesting antianginal and antiischaemic effects of the treatment. These effects seem to be related to a decrease in myocardial oxygen consumption. At the maximum pacing rate all patients experienced anginal pain, myocardial lactate extraction changed to production, and the magnitude of ST segment depression and myocardial oxygen consumption increased to the same values as during control pacing, indicating that myocardial ischaemia during treatment with spinal cord stimulation gives rise to anginal pain. Thus, the treatment does not deprive the patient of a warning signal during myocardial ischaemia.

We thank our medical statistician, Anders Odén, for expert professional advice and for careful and precise statistical calculations and for guidance regarding their interpretation.

1 Gybels JM, Kupers R. Central and peripheral electrical stimulation of the nervous syutem in the treatment of chronic pain. Acta Neurachir 1987; nervous system

2 Siegfried J, Lazorthes $Y$. Long-term follow-up of dorsal cord stimulation for chronic pain oyndrome after multiple lumbar operations. Appl Neurophysiol 1982;45:201-4.

3 Augustinsson LE, Carlsson CA, Holm J, Jivegard L. Epidural electrical stimulation in severe limb ischemia. Ann Surg 1985;202:104-10

4 Cook AW, Oygar A, Baggenutos P, Pacheco S, Kleriga E. Vascular disease ox extremities. Electrical stimulation of spinal cord and posterior roots. $N$ Y State 9 Med 1976;76:366-8.

5 Jacobs MJHM, Jorning PJG, Beckers RCY, Ubbink DT, van Kleef M, Slaaf DW, et al. Foot salvage and improvements of microvascular blood flow as a result of epidural spinal cord electrical stimulation. I Vasc Surg 1990;12: result

6 Mannheimer C, Augustinsson L-E, Carlsson C-A, Manhem K, Wilhelmsson

C. Epidural opinal electrical stimulation in severe angina pectoris. Br Heart 9 C. Epidural spina

7 Sanderson JE, Brooksby $P$, Waterhouse D, Palmer RBG, Neubauer $K$.
Epidural apinal electrical stimulation for severe angina: a study of its effects on symptoms, exercise tolesance and degree of ischaemia. Eur Hean 9 1992;13:628-33.

8 Sowton GE, Balcon R, Cross D, Frick MH. Measurement of the angina threehold using atrial pacing. Cardiovasc Res 1967;1:301-6.

9 Forrester JS, Helfant RH, Pasternac A, Amuterdam EA, Most AS, Kemp HG, et al. Atrial pacing in coronary heart disease. Am 9 Cardiol 1971;27:237-42.

10 Mannheimer C, Carison C-A, Bmanuelsson H, Vedin A, Waagatein $F_{1}$ Wilhelmus $C$. The effects of transcutaneous electrical nerve stimulation in patients with ievere angina pectoris. Circulation 1985;71:308-16.

11 Ganz W, Tamusa K, Marcus HS, Donoso R, Yoahida S, Swan HJC. Measurement of coronary sinus blood flow by continuous thermodilution in man. Circulation 1971;48:181-95.

12 Bradley JV. Distribution-free statistical tests. London: Prentice-Hall, 1968 68-86.

13 Lehmann EL. Testing statistical hypotheses. New York: Wiley, 1986:233-7.

4 Oden A, Wedel H. Arguments for Fiaher's permutation test. Annals of Statistics 1975;3:518-20.

15 Ihlen $\mathrm{H}$, Simonsen S, Vatne K. Reproducibility of ischaemic lactate metabolism during atrial pacing in man. Cardiology 1983;70:177-83.

16 Jackson G, Atkinson L, Oram S. Improvement of myocardial metaboliam in coronary arterial disease by beta-blockade. Br Hear Y 1977;39:829-33.

17 Thadani U, Lewis JR, Mathew TM, Weat RO, Parker JO. Reproducibility of clinical and hemodynamic parameters during pacing etress teating in clinical and hemodynamic parameters during pacing

18 Remme WJ. Myocardial lactate metaboliom-the golden standard when evaluating interventions in ischemia. Eur Hear 9 1992;13(Abstract suppl) P1963.

19 Cohen LS, Elliott WC, Klein MD, Gorlin R. Coronary heart disease. Clinical cinearteriographic and metabolic correlations. Am o Cardiol 1966;17; 153-68.

20 Neill WA, Kremkau EL, Oxendine JM, Phelpa NC. Criteria for detecting inchemic myocardial hypoxia from lactate and pyruvate data during atrial pacing in humans. I Lab Clin Med 1974;83:428-32.

21 Gertz EW, Wisnesti JA, Neese $R$, Houser $A$, Korte $R$, Bristow JD. Myocardial lactate extraction: Multi-determined metabolic function. Circulation 1980;61:256-61.

22 Emanuelsson $\mathrm{H}$, Mannheimer $C$, Waagrein F, Wilheimuson C. Catecholamine metabolism during pacing-induced angina pectoris and the effect of transcutaneous electrical nerve stimulation Am Heart $1987 ; 114: 1360-6$.

23 Mannheimer C, Emanuelsson H, Waagitein F, Wilhelmeson C. Influence of naloxone on the effects of transcutaneous electrical nerve itimulation naloxone on the effects of transcutaneous electrical netve otimulatis
(TENS) in pacing-induced angina pectoris. Br Hear 9 1 1989;62:36-42.

24 De Landiherre C, Mannheimer C, Habets A, Guillame M, Bourgeois I Augustinsson L-E, et al. Effect of spinal cord stimulation on regional myocardial perfusion assessed by positron emission tomography. Am F Cardiol 1992;69:1143-9.

25 Hosobuchi Y. Electrical stimulation of the cervical spinal cord increases cerebral blood flow in humans. Appl Neurophysiol 1985;48:372-6.

26 Lundberg T, Kjartansson J, Samuelsson U. Bffect of electrical nerve stimulation on healing of ischaemic skin flaps. Lancet 1988;ii:712-4.

27 Mosher P, Rous J, McFate PA, Show RF. Control of coronary blood flow by an autoregulatory mechanism. Circ Res 1964;14:250-9.

28 Miller WL, Belardinelli L, Bacchus A, Foley DH, Rubio R, Berne RM. Canine myocardial adenosine and lactate production, oxygen consumption, and coronary blood flow during stellate ganglia stimulation. Circ Res 1979;45:708-18.

29 Krabb RM, Ely SW, Bacchus AN, Rubio R, Berne RM. Consitent parallel relationships among myocardial oxygen conoumption, coronary blood flow, and pericardial infusate adenosine concentration with various interventions and $\beta$-blockade in the dog. Circ Res 1983;53:33-41.

30 Feigl BO. Coronary physiology. Physiol Rev 1983;63:1-205.

31 Robertson RM, Bernard Y, Robertson D. Arterial and coronary ainus catecholamines in the course of opontaneous coronary artery opaum. Am Heart \% 1983;105:901-6.

32 Chandler MJ, Brennan TJ, Garrison DW, Kim KS, Schwartz PJ, Forman RD. A mechanism of cardiac pain euppression by upinal cord utimulation: implications for patients with angina pectoris. Eur Heart I 1993;14:96-105.

33 Kroget K, Schipke J, Thamer V, Heusch G. Postatenotic ischaemic myocardial dyefunction induced by peripheral nociceptive itimulation. Eur Heart $\% 1989 ; 10: 179-82$

34 Blomberg S, Curelaru I, Emanueleson H, Herlitz J, Ponten J, Ricksten SE. Thoracic epidural anesthesia in patients with unstable angina pectoris. Eur Hean o 1989;10:437-44.

(Accepted 28 May 1993)

\section{Adverse drug reactions: who is to know?}

\section{Martin Cook, R E Ferner}

Dudley Road Hospital, Birmingham B18 7QH

Martin Cook, medical student

R E Ferner, consultant physician

\section{Correspondence to:}

Dr R E Ferner.

$B M F$ 1993;307:000-0
Adverse drug reactions can be difficult to detect, and patients may be adamant that an event is due to drug treatment when few experts would agree. None the less, it is at least prudent to discover whether patients believe that they have suffered from previous treatment, and it can be imperative to do so if the patient is not to be exposed to needless risk. Once a reaction has been elicited it should be recorded.'

To study how effectively adverse reactions are elicited in hospital we compared the number of reactions recorded in routine medical notes and on prescription charts with the numbers discovered using a simple questionnaire. We also examined whether doctors recorded reports on well established reactions more often than unlikely ones.

\section{Subjects, methods, and results}

The subjects were 437 patients (254 men and 264 surgical patients) on the general medical, general surgical, and orthopaedic wards who were sufficiently awake and lucid to answer questions. An interpreter helped when necessary. Each patient was asked: Have any medicines or tablets ever disagreed with you or caused an allergy? If so, what was the drug, and what happened? Have you ever needed treatment by a doctor or at a hospital for a reaction to a medicine or tablet? If so, what was the drug, and what happened? Are you able to take aspirin or penicillin? When a 